\title{
La Asociación Madres de Plaza de Mayo y la constitución de filiales en los años ochenta
}

\section{The Asociación Madres de Plaza de Mayo and the constitution of subsidiaries in the eighties}

\author{
Paula Zubillaga \\ paulazubillaga@gmail.com \\ Instituto de Desarrollo Humano - Universidad \\ Nacional de General Sarmiento / CONICET, \\ Argentina
}

Recepción: 23 Noviembre 2019

Aprobación: 09 Marzo 2020

Publicación: 01 Marzo 2021

Cita sugerida: Zubillaga, P. (2021). La Asociación

Madres de Plaza de Mayo y la constitución de

filiales en los años ochentas. Sociohistórica, 47,

e120. https://doi.org/10.24215/18521606e120

\begin{abstract}
Resumen: Las organizaciones defensoras de los derechos humanos que actúan en la Argentina se caracterizan por su despliegue en distintos puntos del país a partir del accionar del conjunto de sus filiales. En la década del ochenta, Madres de Plaza de Mayo -constituida en Asociación en 1979- poseía una veintena de filiales. Estas se establecieron al menos desde 1982 en distintas provincias de la Argentina. A partir de documentos de dicha Asociación, y sobre la base de una extensa bibliografía, en este artículo nos acercamos a las causas de su expansión territorial y la consiguiente formación de filiales en localidades tan diversas como Alto Valle, Tucumán, La Rioja, Mar del Plata, Rosario o Santa Fe. De esta forma, observamos que dichas causas deben buscarse tanto en las estrategias de la Asociación como en los propios contextos locales donde se fundaron.
\end{abstract}

Palabras clave: Movimiento de derechos humanos, Madres de Plaza de Mayo, Filiales.

\begin{abstract}
The human rights organizations that act in Argentina are characterized by their deployment in different parts of the country from the actions of all their subsidiaries. In the eighties, Madres de Plaza de Mayo -established in Association in 1979- owned about twenty subsidiaries. They were constituted at least since 1982 in different provinces of Argentina. Based on documents from said Association and based on an extensive bibliography, in this article we approach the causes of its territorial expansion and the consequent formation of subsidiaries in locations as diverse as Alto Valle, Tucumán, La Rioja, Mar del Plata, Rosario or Santa Fe. In this way, we observe that these causes must be sought both in the Association's strategies, and in the local contexts where they were founded.
\end{abstract}

Keywords: Human rights movement, Madres de Plaza de Mayo, Subsidiaries.

\section{INTRODUCCIÓN}

La magnitud y las características novedosas de represión desplegada durante la última dictadura argentina (1976-1983) llevaron a la conformación, en distintos puntos del país, de grupos de oposición y denuncia 
al accionar terrorista del Estado. En algunos casos, esto supuso la creación de organizaciones netamente locales y, en otros, la constitución de filiales de organizaciones defensoras de los derechos humanos nacidas en Buenos Aires. En esta línea, si bien es cierto que el movimiento de derechos humanos en la Argentina ha sido objeto de numerosas investigaciones que ya han merecido algunos balances (Zubillaga, 2016), en general, y como ya lo han señalado otros investigadores (Águila, 2015; Alonso, 2015 y 2018; Kotler, 2014), la mayoría de las producciones suelen centrarse en la dinámica de la Capital Federal y en la ciudad de La Plata, e identifican sólo a ocho organizaciones como las integrantes del movimiento; ${ }^{1}$ son relativamente escasos aún los estudios que den cuenta del movimiento y sus diversas expresiones en otras regiones o ciudades del país (Zubillaga, 2019a).

En la década del ochenta, la Asociación Madres de Plaza de Mayo en particular poseía una veintena de filiales en distintas provincias del país y, si bien existe una extensa bibliografía sobre dicha organización, poco es lo que se conoce sobre sus filiales. ${ }^{2}$ En términos generales, estas investigaciones han permitido diferenciar el accionar y la postura de Madres de Plaza de Mayo con respecto a otras organizaciones e identificarla con una posición más radicalizada y asumida en términos políticos más tempranamente. Sin embargo, estos trabajos no han hecho foco en la política de expansión de la Asociación y en la consiguiente constitución de filiales en distintos puntos del país.

En los últimos años, una serie de investigaciones vienen reflejando la multiplicidad y diversidad de sujetos y prácticas del movimiento de derechos humanos, con el fin de complejizar la visión predominante capitalina y considerar de modo más completo las diferentes experiencias históricas. La necesidad de salir del contexto capitalino y explorar otros casos, a fin de aportar las particularidades locales al conjunto de la historia del país, se ve reflejada en investigaciones realizadas -algunas con mayor profundidad que otras- para pensar la historia del movimiento en Mar del Plata (Zubillaga, 2019b), La Pampa (Morales, 2010), Jujuy (Castro, 2004), Tucumán (Kotler, 2014 y 2018), Rosario (Ochoa, 1996; Scocco, 2016 y 2018), Córdoba (Oviedo y Solis, 2007; Solis 2011, 2014 y 2016), Santa Fe (Alonso, 2006, 2008 y 2011), Viedma-Carmen de Patagones (Del Carmen y Chironi, 2016), El Bolsón (Mereb, 2018), Neuquén y Alto Valle (Areta, 2002; Azconegui, 2009 y 2011; Mombello, 2003), como también en los análisis de la constitución de las redes trasnacionales del movimiento (Sikkink, 1996 y 2003) o los casos de defensa de los derechos humanos en Francia (Franco, 2008) y España (Jensen, 2010).

La narrativa académica "clásica" -en tanto típica o característica- (Alonso 2015 y 2018) fue definiendo las agrupaciones que debían considerarse parte del movimiento de derechos humanos e hizo que fuera imposible pensar en otras organizaciones que no fueran las incluidas en el listado de "los ocho organismos de derechos humanos", como parte de dicho movimiento. Esta mirada dejó fuera de la interpretación no sólo a diversas agrupaciones surgidas en distintas localidades del país sino también el análisis de la constitución de filiales de las nacidas en la Capital Federal. Esto se relaciona a su vez con otra característica de la visión clásica forjada desde los años ochenta, como la trasposición de lo que ocurrió en Buenos Aires al conjunto del país. Es decir, la historia de una zona específica de la Argentina como representativa del todo. Así, los casos locales, cuando aparecen en esa narrativa, lo hacen como réplica de lo que previamente se presenta como nacional, pero que no es más que la historia de la zona capitalina. ${ }^{3}$ En esta línea, consideramos que, pese a los avances, aún existen relativamente pocas investigaciones sobre la creación, actuación e impactos de las filiales y de las agrupaciones netamente locales en otras ciudades por fuera de las nombradas.

El relativamente más reciente énfasis en lo local viene abordando el tema a partir de una serie de preguntas que nos resultan fundamentales. ¿Cómo fue el surgimiento y el desarrollo del movimiento de derechos humanos fuera del ámbito capitalino? ¿En qué ciudades y por qué se conformaron filiales de organizaciones nacidas en la Capital Federal y en cuáles y por qué razón se formaron agrupaciones netamente locales defensoras de los derechos humanos? ¿Cuál es el grado de autonomía/dependencia que han sostenido? ¿Qué las ha definido como "filiales"? ¿Han recibido directivas político-ideológicas y/o apoyo económico? ¿Qué vínculo se estableció entre las organizaciones de la Capital Federal y las nacidas en otras localidades? ¿Fue/ es un actor relevante el movimiento de derechos humanos en otras localidades fuera de la Capital Federal? ¿Cuáles fueron los modos de organización y acción en las distintas geografías? 
Un claro ejemplo de la diversidad de experiencias y periodizaciones del movimiento, y de los aportes de una nueva mirada sobre él, es el caso de los estudios sobre la agrupación Madres de Plaza de Mayo. Investigaciones recientes evidencian que las filiales de la Asociación tuvieron surgimientos y desarrollos específicos en distintas ciudades de la Argentina, como Mar del Plata, Tucumán, Neuquén, Santa Fe y Rosario. Estas investigaciones demuestran que en diversas localidades el proceso de nacimiento de Madres de Plaza de Mayo se originó en el desprendimiento o distanciamiento de otra organización en los años ochenta, en algunos casos durante la última dictadura y en otros en la posdictadura. En el caso de provincias del sur del país, la Asamblea Permanente por los Derechos Humanos (APDH) “Alto Valle y Neuquén” -constituida en 1976- sufrió una fractura que dio origen a la delegación local de la Asociación de Madres de Plaza de Mayo en 1982 (Azconegui, 2009). En Tucumán, por su parte, la organización Familiares de Detenidos por Razones Políticas, primera organización de derechos humanos de dicha localidad, conformada en 1977, sufrió una primera división en 1981, que dio origen a la agrupación Madres de Detenidos Desaparecidos de Tucumán, en línea con la Asociación liderada por Hebe Pastor de Bonafini, que en 1983 constituyó la filial Tucumán de Madres de Plaza de Mayo (Kotler, 2014 y 2018). En el caso de Mar del Plata, durante la última dictadura se constituyó una organización defensora de los derechos humanos integrada por familiares de detenidos-desaparecidos con distinto vínculo sanguíneo, denominada Madres, Familiares y Abuelas de Detenidos Desaparecidos de Mar del Plata. Se conformó entre 1976 y 1977 y su accionar se extendió hasta fines de los años ochenta, tras distintos desprendimientos iniciados a partir del retorno democrático y de la conformación de nuevos espacios de representatividad a nivel local en línea con organizaciones nacidas en Buenos Aires. De esta forma, producto de estas divisiones, un grupo de mujeres conformó una filial de la Asociación Madres de Plaza de Mayo en Mar del Plata en 1984 (Zubillaga, 2019b). En Rosario, la delegación local de Madres de Plaza de Mayo se formó en 1985 a partir de militantes de Familiares de Desaparecidos y Detenidos por Razones Políticas y Gremiales de Rosario, y en 1995, por algunas diferencias con la conducción de la Asociación, la agrupación rosarina adoptó el nombre de Madres de Plaza 25 de Mayo, en referencia a la plaza rosarina (Scocco, 2016). En el caso de Santa Fe, algunas militantes del movimiento de derechos humanos local formaron en 1987 Madres de Plaza de Mayo en la línea de la Asociación liderada por Hebe Pastor de Bonafini hasta el 2001, año en que se desvincularon por diferencias de criterio (Alonso, 2011).

A continuación, indagaremos en las causas de la constitución de estas filiales, vinculadas especialmente a la política de expansión territorial de la Asociación y a los contextos locales donde se crearon.

\section{La Asociación Madres de Plaza de Mayo y la constitución de filiales}

Para comprender el proceso de constitución de filiales de la Asociación Madres de Plaza de Mayo durante los años ochenta, debe tenerse en cuenta que la creación de gran parte de ellas se dio en el marco de un proceso de redefinición y reposicionamiento de la Asociación, abierto tras la asunción a la presidencia del radical Raúl Alfonsín, y de disputa interna por la conducción de dicha Asociación, liderada por Hebe Pastor de Bonafini desde 1979.

La Asociación, además de tener la intención de construir representatividad, en el contexto de disputas por la territorialidad con otras organizaciones de derechos humanos que también conformaron filiales durante estos años, se encontraba inmersa en debates internos en torno a las estrategias, los discursos y el rol que debía cumplir en el escenario abierto tras la asunción del gobierno elegido en 1983, así como sobre la forma en que debía conducirse y organizarse. ${ }^{5}$ Estos debates llevaron a la necesidad, por parte de la conducción, de buscar apoyos, representatividad y legitimidad en otras ciudades, entre ellas las que se constituirían en filiales en la posdictadura, como Mar del Plata, Rosario y Santa Fe.

Detengámonos en el contexto interno de la Asociación tras el fin de la dictadura, dado que permite comprender la búsqueda de apoyos, por parte de su conducción, por fuera del grupo de mujeres del eje Buenos Aires-La Plata. Las acciones, discursos y reivindicaciones de la Asociación se habían fijado desde su 
nacimiento en confrontación con la dictadura y, en el nuevo contexto -que implicaba nuevas definiciones y con ellas cambios de estrategia-, generaron grandes debates en su interior. En la posdictadura las Madres debatieron sobre sus representaciones en torno al poder, la justicia, la democracia y, sobre todo, el rol que debían cumplir en la nueva etapa abierta tras la asunción de un gobierno elegido democráticamente, y se manifestaron diferentes enfoques que respondían, en parte, a la composición social e ideológica heterogénea de la Asociación. De esta forma, las contradicciones que emergieron tras estos debates, y otros que mencionaremos a continuación, llevaron a la división de las Madres en 1986, momento a partir del cual la relación con las filiales parece estrecharse. ${ }^{6}$ Un elemento que explica la división son las disidencias relacionadas con la creación y alcances de la Comisión Nacional sobre la Desaparición de Personas (CONADEP) y los pedidos de formación de una comisión parlamentaria bicameral para investigar las violaciones a los derechos humanos. Otro punto de debate que explica la separación se vincula con el apoyo o no a la realización del Juicio a las Juntas Militares en $1985 .^{7}$ La continuidad de la realización o no de las Marchas de la Resistencia tras el fin de la dictadura también representó otro tema de debate, al igual que el reconocimiento o no de la militancia de sus hijos y la utilización o no del método de "escrache".

Más profundos fueron, sin embargo, los debates en torno a la aceptación o no de las indemnizaciones previstas por la ley 23466 -sancionada en octubre de 1986, pero que se venía discutiendo desde meses antes- y en torno a las exhumaciones o no de tumbas NN (Zubillaga, 2017). Estos elementos de discusión, sumados a las tensiones por la forma de conducir de la presidenta de la asociación -en la que algunas integrantes veían rasgos de "autoritarismo", "personalismo", "intransigencia", "verticalismo", "centralismo" y/o "beligerancia”-, son los que explican la división de la Asociación y representan parte del contexto interno en el que se crean varias filiales. ${ }^{9}$ El propio grupo disidente decidió elaborar un texto en el que explicaba las razones por las cuales se retiraba; además de marcar una postura distinta en torno a los homenajes a los detenidos-desaparecidos, las exhumaciones de cadáveres y la ley 23466, sostenían:

\footnotetext{
Cuando asume el actual gobierno, elegido por el pueblo, las diferencias entre las madres que hoy formamos Línea Fundadora y las que lidera Hebe de Bonafini se profundizan. Nosotras sostenemos que no existe democracia interna, que hay desborde en el discurso, marcado tinte político partidista en el periódico y en el mismo discurso -que está invariablemente a cargo de la misma persona-, no se cumple con lo resuelto en las sesiones de la comisión directiva, no se acepta el cumplir con lo establecido en los reglamentos -por ejemplo, llamar a asamblea anual donde se consideren memoria y balance; se desvirtúa el proyecto de que las filiales del interior envíen una o dos representantes, una vez al mes, a reuniones de Comisión Directiva con voz y voto en las deliberaciones. (Madres de Plaza de Mayo Línea Fundadora, 1986)
}

De esta forma, en el marco de los debates internos y de las polémicas con otros sectores del movimiento de derechos humanos, se desarrollaron dos identidades político-ideológicas que desembocaron en la división de una agrupación que para 1986 contaba con 23 filiales en todo el país. La constitución de filiales en Mar del Plata, La Rioja, Tucumán y Rosario entre 1983 y 1985 se dio, así, en el contexto del inicio y profundización de la crisis en el interior de la Asociación que llevó a su división, la cual, como hemos visto, se explica por distintas divergencias relacionadas, por un lado, con la postura que debían asumir frente al alfonsinismo fundamentalmente, si apoyar sus avances en materia de verdad y justicia o mantener una línea combativa e intransigente- y, por el otro, con la forma en que debía organizarse y conducirse la Asociación -en especial, si ceñir la conducción a la Capital Federal y La Plata y funcionar como una federación en la que cada filial actuara independientemente de las otras o mantener la estructura como estaba, para que la fuerza política que se había logrado construir en todo el país no se viera debilitada-. Un ejemplo de la importancia que la conducción comienza a darles a las filiales durante la posdictadura, y especialmente tras su división en 1986, son los viajes al exterior que la Asociación realizó durante los años ochenta para difundir su lucha y conseguir apoyo internacional. Entre 1978 -año del primer viaje realizado como Asociación-y 1986, la mayoría de las integrantes de la agrupación que participaron en los viajes luego formaron Madres de Plaza de Mayo-Línea Fundadora. A partir de ese año comienzan a viajar, acompañadas por alguna mujer de la Comisión Directiva, 
representantes de las filiales de Mendoza, Concordia, Gualeguaychú, Neuquén y Mar del Plata, y en menor medida de Tucumán y Rosario. ${ }^{10}$

Claramente, no sólo Madres de Plaza de Mayo modificó en la posdictadura sus alineamientos y estrategias. El resto de las organizaciones de derechos humanos no estuvieron exentas de debates, rupturas y conflictos. Ciertos organismos cambiaron sus estrategias, otros perdieron algo de protagonismo en el espacio público y algunos, como las Madres lideradas por Pastor de Bonafini, decidieron mantener una confrontación directa y de denuncia permanente. Es evidente que la llegada de un gobierno nacional elegido democráticamente marcó una nueva situación y debates en el movimiento que explican en parte los reacomodamientos en su interior y la búsqueda de nuevos puntos de apoyo. ¿Había que reclamar del mismo modo? ¿Había que sumar nuevos reclamos? ¿Había que participar de las iniciativas oficiales?

Ahora bien, el contexto interno de la Asociación, de debates, quiebres y nuevas estrategias, no explica por sí solo la constitución de filiales, proceso que respondió también a los contextos locales. Las últimas investigaciones muestran que la Asociación Madres de Plaza de Mayo tuvo recorridos dispares fuera del eje Buenos Aires-La Plata. En distintas localidades del país el proceso de nacimiento se dio a partir del desprendimiento o distanciamiento de otra organización en los años 80 , en algunos casos durante la dictadura -como en Tucumán y Alto Valle y Neuquén- y en otros, posterior a ella -como en Mar del Plata, Rosario y Santa Fe-.En el caso de Neuquén, donde la constitución de la filial se dio tempranamente, las causas no estuvieron relacionadas con los debates y desafíos que representó el nuevo contexto democrático, como en cierta medida ocurrió en Mar del Plata y Rosario, sencillamente porque la delegación se conformó durante la dictadura, en 1982. Asimismo, el recorrido allí fue distinto, en parte por el apoyo brindado al movimiento de derechos humanos por parte de la Iglesia Católica neuquina, la cual proporcionó una importante red de relaciones, contención, ayuda económica, legitimidad y canales de expresión para su discurso. Recordemos que en Neuquén se constituyó a mediados de 1976 una filial de la APDH por iniciativa de Jaime de Nevares -miembro fundador de la APDH en Buenos Aires- y luego, una comisión de familiares, entre quienes predominaban las madres de detenidos-desaparecidos. Estas últimas, sin embargo, no tenían una voz que las diferenciara del resto de los miembros de la APDH o de los familiares, junto a quienes llevaban adelante las denuncias. Tras la derrota de Malvinas, en un contexto de resurgimiento de antiguas lealtades políticas, las diferencias en el interior del grupo se hicieron evidentes, y las madres de Alto Valle y Neuquén estrecharon sus vínculos con la Asociación Madres de Plaza de Mayo, cuyo estilo de acción era más cercano al que buscaban desarrollar (Azconegui, 2009 y 2011). En Tucumán, por su parte, la conformación de la filial tras el desprendimiento de la organización Familiares se vincula con los cuestionamientos que algunos miembros comenzaron a hacer respecto a la "inmovilidad" del organismo, la ineficacia de su accionar y la necesidad de "salir a la calle", de ocupar el espacio público, debate que no parece haber estado presente en Mar del Plata, puesto que en la ciudad balnearia el espacio público fue ocupado tempranamente, aunque es cierto que estas dos filiales comparten en su historia la incorporación de mujeres que no eran madres del detenidodesaparecido por el que reclamaban justicia (Kotler, 2018).

Así, al igual que en las localidades ya mencionadas, la filial de Mar del Plata surgió como un desprendimiento de otra organización. En este caso se formó en la posdictadura, tras la división de Madres, Familiares y Abuelas de Detenidos Desaparecidos de Mar del Plata, la primera organización de la ciudad surgida durante la última dictadura, a raíz del accionar represivo desplegado por las Fuerzas Armadas, la policía y la Concentración Nacional Universitaria (CNU). ${ }^{11}$ A causa de los debates que se venían desarrollando, y los que surgieron en el contexto de los gobiernos radicales elegidos democráticamente en la ciudad, la provincia y la nación, y a partir de la diversificación de los objetivos de quienes componían esa primera organización, algunos de sus integrantes se fueron vinculando con distintas agrupaciones existentes del movimiento de derechos humanos y conformaron filiales de ellas. Así, un grupo de mujeres marplatenses se alineó con lo planteado por las Madres de Plaza de Mayo y formó una filial local de dicha Asociación en 1984. Esto se dio en el contexto de una serie de debates suscitados en el interior del grupo en torno a las 
medidas del gobierno de Raúl Alfonsín -sobre todo la constitución de la CONADEP, el Juicio a las Juntas y la ley 23466 de reparación económica para cónyuges e hijos de detenidos-desaparecidos-, los provocados a raíz de las consignas que debían seguir manteniéndose en la posdictadura -en especial "Aparición con vida”y por la realización o no de exhumaciones de tumbas NN (Zubillaga, 2017 y 2019b).

En Rosario, la idea de conformar una filial en la posdictadura, un año después de su fundación en Mar del Plata, surgió de algunas madres que ya asistían a las marchas en la Capital Federal y de algunas integrantes de una nueva comisión directiva de Familiares, que las acompañaron en la iniciativa de diferenciarse de posturas más moderadas de otros organismos y que conformaron su Grupo de Apoyo (Scocco, 2016). Al igual que en Mar del Plata, parece haber sido fundamental para su constitución, en 1985, la decisión de mantener la consigna "Aparición con vida" y de no apoyar el accionar de la CONADEP. En Santa Fe, su emergencia estuvo en parte relacionada con la disolución de la APDH y con la debilidad creciente de Familiares en la posdictadura, lo que habría llevado en 1987 a afianzar el vínculo que se tenía con la línea liderada por Hebe Pastor. Su constitución tardía respecto de las demás filiales quizás pueda explicarse en parte por la escasa cantidad de participantes, lo que hacía aconsejable no formar agrupaciones que no pudieran reunir un mínimo de militantes para sostener las acciones colectivas. Esa razón puede haber dejado de ser válida en el contexto de crisis de sentido y de organización del movimiento santafecino a mediados de los años ochenta (Alonso, 2011). De esta forma, vemos que la opción por la acción directa, propia de la Asociación, es una de las causas en distintas localidades, aunque no estuvo en discusión en otras ciudades, como Mar del Plata, lo que permite afirmar nuevamente que las razones por las cuales distintos grupos de mujeres decidieron constituir una filial de la Asociación varió según los contextos. En otras ciudades que aún no han sido estudiadas sistemáticamente, como La Rioja, las integrantes de la filial han sostenido que se conformaron a partir de la relación previa con la Asociación -indispensable en todos los casos analizados-. Formalizaron la constitución de la filial en diciembre de 1983 a partir de las "sugerencias" de las Madres de Buenos Aires, por la "necesidad" de trabajar juntas y gracias al apoyo de otros familiares de detenidos-desaparecidos y exdetenidos. Asimismo, destacan la importancia de la consigna "Aparición con vida", la cual, como mencionamos, fue decisiva en la opción por la constitución de la filial en Rosario y en Mar del Plata. ${ }^{12}$

Consideramos, así, que la conformación de filiales obedece a dinámicas tanto nacionales como locales. Si bien puede hablarse de una política de expansión durante la dictadura y en la posdictadura de la Asociación Madres de Plaza de Mayo de Buenos Aires hacia otras ciudades del país, no es menos cierto que se conformó en algunas ciudades a raíz también de las disputas, las alianzas y las estructuras de oportunidades políticas locales. De esta forma, mientras en varias localidades el proceso de nacimiento de la filial se originó a partir del desprendimiento o distanciamiento de otra organización, en otras ciudades donde el movimiento era activo, como Córdoba, no se organizó una delegación de la Asociación. ${ }^{13}$

Como mencionamos en la introducción, la Asociación Madres de Plaza de Mayo estableció tempranamente, durante la dictadura, que las filiales podían ser regionales o locales y que debían contar con un grupo de al menos cinco personas, enviar una solicitud a la Comisión Directiva, fijar un domicilio legal y adherir formalmente a la Declaración de Principios y al Estatuto de la Asociación. Constituirse en filial, ya sea durante la dictadura o después de ella, implicaba defender el apartidismo, adherir a la consigna "Aparición con vida", socializar la maternidad y adherir a los Principios de la mencionada Declaración, que incluía, entre otros, manifestarse "contra la violencia y contra cualquier tipo de terrorismo", respetar los derechos fundamentales de las personas y rechazar la injusticia, la opresión, la tortura y los asesinatos. En cuanto a las directivas políticas, cabe destacar que en el Estatuto de la Asociación Madres de Plaza de Mayo se dejaba establecido que, si bien las filiales podían establecer contactos y realizar actividades con otras instituciones, las declaraciones públicas debían ser consultadas y aprobadas previamente por la Comisión Directiva Nacional de dicha Asociación (Asociación Madres de Plaza de Mayo, s/f; 1979a; 1979b y 1979c). Asimismo, debe destacarse que constituir una filial no implicaba financiamiento económico, como en cambio sí brindaron otras organizaciones a sus delegaciones. ${ }^{14}$ 
Siguiendo lo expuesto hasta aquí, se puede pensar que, por un lado, la constitución de filiales obedeció a los propios contextos locales y que, por otro lado, existió una estrategia de ampliación de la base territorial por parte de la Asociación para configurar un reclamo político-social que se ubicara no sólo en la capital del país, sino también en distintos puntos del territorio nacional, que explica en parte las causas de la formación de filiales. Antes de constituirse como una asociación civil sin fines de lucro en 1979, en un escrito destinado a madres de detenidos-desaparecidos sostenían que "Cuando haya respaldo, empezaremos la campaña en el país" (Madres de Plaza de Mayo, s/f). Esto se evidencia con más fuerza desde 1980, año en que la Asociación, ya conformada como tal, comienza a incluir, en distintos documentos, el objetivo inmediato de establecer vinculaciones con el Gran Buenos Aires y el interior, a partir de la creación de filiales, la coordinación de tareas, la realización de Encuentros en el "interior del país" como los realizados en Buenos Aires y la impresión y distribución de su estatuto y de material informativo en los viajes a otras localidades (Madres de Plaza de Mayo, 1980). A partir del análisis de documentos de la Asociación, observamos que en la posdictadura este objetivo sigue presente, como lo demuestra el texto con las conclusiones del Encuentro Nacional desarrollado en 1984 en Tucumán:

Uno de los objetivos de las Madres de Plaza de Mayo es la formación de filiales independientes en cada localidad. Resaltando que las nuevas filiales recuperaron Madres que se habían alejado (Madres de Plaza de Mayo, 1984)

El análisis de este documento permite sostener no sólo que era un objetivo claro de la Asociación la creación de delegaciones que defendiesen su postura y reclamos en distintos puntos del país, sino que también eran conscientes (y lo reconocían) de que el regreso a un contexto de democracia representativa no había cumplido con las expectativas de varias mujeres que en un principio habían salido en busca del familiar desaparecido (en su mayoría, el hijo) y que luego habían abandonado la búsqueda o la agrupación de la que habían formado parte, fundamentalmente por la desilusión y frustración provocadas por el hecho de que no apareciera con vida el familiar tras la asunción del gobierno de Raúl Alfonsín.

Por otro lado, y no siendo excluyente, en distintas ciudades, como Mar del Plata o Rosario, se habían conformado grupos compuestos por familiares de detenidos-desaparecidos. En los reposicionamientos abiertos tras la asunción del gobierno elegido democráticamente, sectores de ellos optaron por alinearse con una asociación que en los últimos años no sólo venía obteniendo reconocimiento internacional, sino que también la prensa gráfica de tirada nacional registraba sus acciones e incluso las reconocía como un grupo opositor importante a la dictadura. A su vez, la Asociación recibía el apoyo de distintos sectores juveniles y reconocimiento en el interior del movimiento de derechos humanos. ${ }^{15}$ Consideramos que el conocimiento de esta situación puede haber permitido que mujeres de distintas localidades viesen la Asociación como una agrupación fuerte, representativa, y que esto haya tornado favorable la inclinación a la conformación de una filial en sus ciudades, puesto que su creación podía lograr que sus demandas fueran más visibles y legítimas a nivel local.

Es probable que la ubicación de la Asociación en un polo crítico frente al gobierno de Alfonsín también haya propiciado la extensión de filiales a partir de 1984. A su vez, es posible que la opción de formar una delegación se viera favorecida por el uso del pañuelo blanco -símbolo que se había extendido durante la dictadura entre las mujeres del movimiento de derechos humanos, aunque no formaran parte de Madres de Plaza de Mayo, como ocurrió en Alto Valle y Mar del Plata-, por la fuerte imagen de su presidenta, Hebe Pastor de Bonafini, quien viajó a distintas ciudades de la Argentina durante los años ochenta para establecer vínculos con distintos grupos de familiares movilizados, y por la constante organización o participación de la Asociación en acciones registradas por la prensa, en contraste con lo que algunos familiares de detenidosdesaparecidos consideraban como el "inmovilismo" de otras organizaciones.

Debe señalarse que la Asociación Madres de Plaza de Mayo venía teniendo contactos desde la dictadura con familiares de detenidos-desaparecidos que habían salido a denunciar y reclamar el esclarecimiento de los crímenes en distintas ciudades, como Tucumán, Mar del Plata, Rosario y La Rioja. Así, incluso antes de que se 
constituyeran formalmente en filiales, la Asociación difundía acciones colectivas desarrolladas por los grupos de familiares de las distintas localidades en su boletín informativo mensual, en algunos casos reproduciendo o tomando como fuente noticias publicadas en diarios locales -como El Independiente de La Rioja, El Atlántico de Mar del Plata o La Calle de Concepción del Uruguay- o de tirada nacional. Pero la relación no se limitaba a la difusión de sus acciones, puesto que distintas integrantes de la Asociación, pero en especial su presidenta, participaban en numerosas acciones organizadas en ciudades fuera de la Capital Federal donde existían filiales de otras agrupaciones u organizaciones locales, como marchas, misas y otras acciones colectivas (Madres de Plaza de Mayo, marzo de 1982, p. 18; mayo de 1982, p. 14; febrero de 1983, p. 3; abril de 1983, pp. 4-10; mayo de 1983, p. 12; octubre de 1983; diciembre de 1983; septiembre 1984, pp. 18-25). A su vez, algunas mujeres venían participando desde 1981 de los Encuentros Nacionales realizados por las Madres en distintas localidades y en las Marchas de la Resistencia iniciadas ese mismo año, sin haberse constituido aún una filial en su lugar de procedencia.

En el año 1983 parecen acrecentarse las reuniones de la Comisión Directiva de la Asociación con madres de detenidos-desaparecidos de distintas localidades. A modo de ejemplo, puede citarse la reunión mantenida en la Casa de las Madres en Buenos Aires entre dicha Comisión Directiva y mujeres provenientes de Mar del Plata, Tucumán, Jujuy, San Juan y Chaco. Según informó la Asociación, en dicha reunión las madres "del interior" manifestaron la necesidad de que representantes de la Comisión Directiva se hiciesen presentes en las distintas localidades con mayor frecuencia (Madres de Plaza de Mayo, mayo de 1983, pp. 8-9).

A fines de 1984, la Asociación Madres de Plaza de Mayo ya contaba con 21 filiales en distintos puntos del país, cantidad que iría aumentando en los siguientes años. Sin embargo, la organización de filiales ya no es presentada en los escritos como en el año anterior, es decir, como una necesidad o requerimiento de las ciudades "del interior", sino como algo logrado por el trabajo de difusión de la propia Asociación:

Asistimos con satisfacción a la respuesta del interior, organizando filiales de Madres de Plaza de Mayo que premian nuestro incansable traslado a todos los puntos del país para tomar contacto con los familiares afectados, llevando planteos y planes de trabajo para realizar en conjunto (...) Seguiremos llevando nuestra sed de justicia y castigo a todos los puntos del país (...) La voz de Hebe que nos representa totalmente ha sido oída con apoyo masivo del pueblo en cada lugar que se visitó (Madres de Plaza de Mayo, septiembre de 1984, p. 18).

El análisis de los documentos de la época producidos por la Asociación en los cuales se hace referencia al "interior" nos permite pensar que formaba parte de su estrategia absorber las experiencias previas de organización en las distintas localidades. Es decir, se puede pensar que existió el objetivo de construir representatividad en distintos puntos del país y que este se podía lograr, o bien a través de la conformación de un grupo nuevo de personas que se animaran a participar en el nuevo contexto o bien atrayendo a personas con una experiencia local propia de organización. Esto se debe a que, en algunas localidades, algunas mujeres hicieron la denuncia por la desaparición del hijo frente a algún organismo de derechos humanos o posteriormente frente a la CONADEP, pero no participaron en acciones colectivas y, en otros casos, se acercaron a las agrupaciones para participar de alguna acción concreta, como más tarde ocurrió con las conmemoraciones del golpe de Estado, que se convirtió para algunas mujeres en el único día de movilización. Así, la Asociación pretendía recuperar o atraer a estas mujeres, tras el retorno a un contexto democrático, para ampliar su influencia y representatividad, a partir de la creación de filiales que respondieran a su línea.

Si tenemos en cuenta que hacia 1986-1987 la Asociación ya contaba con veinticuatro filiales en todo el territorio nacional, es evidente entonces que en los años ochenta diversos núcleos de familiares de detenidosdesaparecidos encontraron en las Madres de Plaza de Mayo un referente en la lucha contra la dictadura y por los derechos humanos, en especial el derecho a la vida -asociado fundamentalmente a la aparición con vida de los detenidos-desaparecidos- y, por ende, estrecharon sus vínculos con ellas. Algunos investigadores han sostenido que "desde la Plaza de Mayo surgieron muchas otras plazas que juntaron a muchas otras madres de desaparecidos, dispersas en el interior del país" (D'Antonio, 2007, p. 295). En algunas localidades, como es el caso de Mar del Plata, esa "otra plaza”, ese espacio público donde visibilizar la problemática, ya estaba siendo 
ocupado por una agrupación local, por lo que puede decirse que en algunas ciudades el espacio público, la calle, primero fue ocupada por una agrupación netamente local y, luego, el espacio se resignificó y fue ocupado también por una filial local de uno de los organismos nacidos en la capital del país y que para entonces ya era reconocido fuera de las fronteras nacionales. ${ }^{16}$ Asimismo, más que "dispersas", se encontraban agrupadas bajo otros sellos.

Cabe destacar que las integrantes de Madres de Plaza de Mayo-Línea Fundadora también parecen haber tenido interés, tras la separación de la Asociación en 1986, en relacionarse con madres de detenidosdesaparecidos de otras localidades, es decir, fuera de la Capital Federal, como se desprende de algunos escritos:

A las reuniones semanales deliberativas (...) serán bienvenidas todas las madres de Capital o Interior que deseen colaborar. Y queremos, también, que las Madres del interior tengan, en esta hoja informativa, su espacio. Esperamos sus palabras.(Madres de Plaza de Mayo-Línea Fundadora, noviembre de 1987, pp. 6-7)

La intención de relacionarse con las "Madres del interior" no debe sorprender, puesto que al producirse la separación, en 1986, gran parte de las filiales permanecieron -al menos por unos años- dentro de la órbita de la Asociación, como Luján, La Rioja, Mendoza, Concordia y Gualeguaychú, además de las ya mencionadas de Tucumán, Rosario y Mar del Plata, o bien se constituyeron bajo dicha órbita, como la santafecina en 1987. Este primer alineamiento en parte se entiende si se tiene en cuenta que la encargada de articular las relaciones con las provincias era Hebe Pastor de Bonafini, en tanto presidenta de la Asociación. Esto le permitió viajar a distintas localidades del país -como Río Cuarto, Rosario o Mar del Plata, entre muchas otras-, relacionarse personalmente y establecer vínculos con las distintas filiales. Si bien podía acompañarla alguna otra integrante, el trato directo era fundamentalmente entre la presidenta y las afiliadas.

Resulta entonces evidente que había un interés real de parte de la Asociación liderada por Hebe Pastor de Bonafini en tejer lazos con familiares movilizados en otras localidades fuera de la capital del país y de la ciudad de La Plata. No obstante, como hemos adelantado, no debe pensarse que la Asociación era la única interesada en mantener vínculos con familiares de distintas localidades y crear delegaciones. ${ }^{17}$

La Asamblea Permanente por los Derechos Humanos, surgida en 1975, contaba a mediados de los años ochenta con delegaciones en distintos puntos del país, ${ }^{18}$ al igual que Familiares de detenidos-desaparecidos ${ }^{19}$ y, aunque en menor medida, Abuelas de Plaza de Mayo -dado lo específico de su objetivo en relación con las otras organizaciones y a que funcionó como una subcomisión dentro de Madres durante mucho tiempo-. ${ }^{20}$ La APDH tenía un gran interés en crear filiales y hacia 1984 ya poseía más de veinte en distintos puntos del país, incluidas distintas localidades de la provincia de Buenos Aires. En el contexto del $10^{\circ}$ aniversario de su creación, la APDH alentaba la formación de "una nueva generación de cuadros intermedios, líderes locales y nacionales” y reivindicaba la existencia de más de cincuenta delegaciones en todo el país:

La trascendencia nacional de nuestro movimiento tiene como acontecimiento inédito, visto desde el interior, el funcionamiento de 53 delegaciones que con sus más y sus menos constituyen la base posible para la sustentación de una red nacional (APDH, marzo 1986, p. 4).

Al igual que Madres de Plaza de Mayo, algunas filiales de la APDH se crearon en la posdictadura, como el caso de la delegación marplatense y la filial de Tucumán -ambas en 1984-, mientras que en otras localidades su constitución se dio tempranamente, como en Neuquén (1976) o Rosario (1979), o durante los años ochenta dictatoriales, como en Santa Fe (1980), Roca (1981) o Viedma (1982).

Los intentos de contactar a familiares de detenidos-desaparecidos por parte del Centro de Estudios Legales y Sociales también datan de muy temprano. Así, los viajes y reuniones del matrimonio Mignone, en Dolores, Mar del Plata y otras ciudades de la provincia de Buenos Aires, muestran el interés por tejer lazos en distintas localidades desde 1980 -año en que terminó de conformarse formalmente como un desprendimiento de la APDH- (CELS, febrero de 1980). 
Por su parte, la Liga Argentina por los Derechos del Hombre, la organización defensora de los derechos humanos más antigua en la Argentina, tenía interés, al menos desde 1978, en expandir su territorialidad, como se desprende de la moción aceptada en el IX Congreso Nacional de ese año en la Capital Federal, en el cual se propuso la creación de 100 filiales en todo el territorio nacional. De esta forma, hacia 1984 tenía filiales en Rosario, Santa Fe, Córdoba, Mendoza, Tucumán y en la Capital Federal, y había establecido vínculos con algunos abogados marplatenses que apoyaban al grupo de familiares de detenidos-desaparecidos (CPM, DIPBA, Legajo 11.739).

En este sentido, sobre la base de lo expuesto hasta aquí, puede pensarse entonces que la formación de filiales de la Asociación Madres de Plaza de Mayo en los años ochenta se debió en parte a su política de expansión y a su disputa con el resto de los organismos de derechos humanos por la ampliación de su territorialidad y el reconocimiento a su trayectoria; pero también, como vimos, se debió a las propias dinámicas locales y los reposicionamientos abiertos en el interior del movimiento de derechos humanos, en algunos casos en el contexto abierto tras la derrota de Malvinas y en otros tras la asunción de los gobiernos elegidos democráticamente en 1983. Es decir, existía una voluntad de conformar delegaciones en distintas localidades, pero en algunos casos esto implicaba luchas por el reconocimiento e imposición de su forma de entender cómo debía tramitarse el pasado. En algunas localidades, la división de alguna organización podía implicar que la cantidad de integrantes no fuera la suficiente como para sostener y garantizar las acciones colectivas. En general, por fuera de la Capital Federal, el número de militantes era relativamente pequeño y la constitución de una filial implicaba fracturas en agrupaciones ya existentes y la creación de nuevas con menos integrantes -entre 10 y 40 personas aproximadamente-. La mayor afinidad con una u otra organización quizás se pueda explicar por las posturas y formas de accionar de cada una, dado que algunas tenían un funcionamiento más burocrático y ligado al ejercicio del derecho, como la LADH, la APDH o el CELS, y otras tenían más presencia en el espacio público, como Familiares o Madres de Plaza de Mayo. Si puede decirse que una especificidad de Madres de Plaza de Mayo era la necesidad manifiesta de no limitarse a gestiones particulares y/o a la vía judicial, como aconsejaban organizaciones como la Liga o APDH, también puede decirse que, en distintas localidades, las acciones desplegadas por la Asociación resultaron un gran atractivo para muchas mujeres. Así, integrantes de las filiales de Neuquén, Mar del Plata y Tucumán han sostenido: "Siempre fuimos muy intransigentes", "Nunca fuimos jurídicas", "Somos más de lo callejero, de lo público, que de lo administrativo burocrático" (Azconegui, 2009; Zubillaga, 2019b; Kotler, 2014 y 2018). A su vez, como mencionamos, Madres de Plaza de Mayo tuvo posturas más radicalizadas y un mayor poder simbólico por el uso generalizado del pañuelo blanco sobre las cabezas para identificarse.

De esta forma, distintos grupos de mujeres en la Argentina optaron por organizarse bajo un sello externo a lo local, pero ya conocido a nivel nacional e internacional, que les diera legitimidad y visibilidad a sus acciones en su escala de actuación, en especial tras la separación de los grupos originales a los que pertenecían, en algunos casos a la APDH y/o Familiares, y en otros, a organizaciones netamente locales. Debe recordarse que constituirse en filial no implicaba un financiamiento de sus acciones de difusión y denuncia por parte de la Asociación conducida desde Buenos Aires, por lo que su conformación no puede pensarse en términos de sostén económico; por el contrario, las integrantes debían colaborar con una cuota mensual. Constituirse en una delegación o filial suponía dar legitimidad a sus discursos y acciones en sus ciudades de actuación, al formar parte de un colectivo mayor.

Las comisiones representativas de las filiales debían conformarse y funcionar de acuerdo con los lineamientos establecidos desde la fundación de la Asociación en Buenos Aires en 1979, es decir, siguiendo lo indicado en el Estatuto, la Declaración de Principios y lo establecido para las filiales de la Asociación Madres de Plaza de Mayo. Como mencionamos, las filiales tenían cierta autonomía, puesto que la Comisión Directiva Nacional establecía que "podrán establecer contactos, realizar actividades comunes y realizar gestiones con otras instituciones de cualquier tipo, siempre que se resguarden los principios y pautas contenidas en la Declaración de Principios y en el Estatuto" (Asociación Madres de Plaza de Mayo, s/f). Sin embargo, se 
establecían ciertos límites para las declaraciones públicas, puesto que debían ser consultadas y aprobadas previamente por dicha Comisión, lo cual revela cierta necesidad de mantener el discurso centralizado por parte de la conducción.

Es importante destacar que, una vez constituidas, las integrantes de las filiales participaban de los diversos encuentros en las distintas localidades donde existían filiales de la Asociación, en tanto eran ámbitos de intercambio de propuestas y de debates de ideas y planes a seguir. En esta línea, los primeros "Encuentros Nacionales" -instancia surgida durante los últimos años de la dictadura- de las Madres de Plaza de Mayo se realizaron en 1981 en La Plata, en 1984 en Santa Fe y Tucumán, y en 1985 en Mar del Plata, La Plata y La Rioja. En el contexto de las disputas por la conducción de la Asociación, los encuentros siguieron realizándose y en 1986 las sedes fueron Neuquén, Buenos Aires, Concordia y Rosario, en 1987 nuevamente Tucumán y en 1989 se realizó una vez más en Neuquén (Madres de Plaza de Mayo, 9 de septiembre de 1984; 23 de junio de 1985; noviembre de 1987 y 2017). Estos encuentros representaban espacios muy importantes para la organización interna y eran muy valorados por las afiliadas; en años posteriores, su discontinuidad fue una de las causas de nuevos desprendimientos de la Asociación. Los Encuentros eran valiosos porque permitían unificar criterios y coordinar acciones. Un ejemplo de ello es que en el XVII Encuentro Nacional reunido en Tucumán en noviembre de 1987, del que participaron distintas filiales, las Madres repudiaron la Conferencia de Jefes de Ejércitos Latinoamericanos pronta a llevarse a cabo en Mar del Plata y criticaron nuevamente al gobierno de Raúl Alfonsín por auspiciar la reafirmación de la Doctrina de Seguridad Nacional; días más tarde, se manifestaron en Mar del Plata en contra de la Conferencia, durante su desarrollo. ${ }^{21}$

Cabe destacar que, en cada Encuentro, además de decidir la siguiente ciudad de reunión -en un intento de federalizarlos-, cada filial presentaba al resto una narración y evaluación de las actividades desarrolladas, y se finalizaba con un documento con posturas en común a difundir. En los Encuentros, las integrantes de las distintas filiales tomaban conocimiento de la situación política y económica en cada provincia. Y se comprometían a desarrollar una serie de actividades hasta el próximo Encuentro Nacional (Asociación Madres de Plaza de Mayo filial Mar del Plata, 2007).

De esta forma, resulta evidente que el desarrollo de prácticas similares en las distintas localidades se debió en parte al intercambio de experiencias realizado en sus Encuentros, los cuales funcionaron no solo para cohesionar al grupo, sino también para afianzar a cada una de las filiales. Consideramos que los circuitos para aprobar las declaraciones, los encuentros sistemáticos y la libertad para realizar actividades y establecer contactos no son cuestiones menores, puesto que entre los debates que desembocaron en la escisión del grupo denominado Línea Fundadora se encontraba el relacionado con si las filiales debían ser independientes o responder a la Comisión Directiva, contexto en el cual la línea liderada por Hebe Pastorde Bonafini buscó afianzar su posición en "el interior".

\section{REFLEXIONES FINALES}

Ciertamente, las organizaciones de derechos humanos no vinculadas a partidos políticos emergieron en América Latina en la década del 60. Los organismos de familiares se fueron multiplicando y obteniendo protagonismo con el correr de los años, a la vez que las mujeres tuvieron una participación fundamental en ellos, y se constituyeron grupos similares a Madres de Plaza de Mayo en distintos países de América. En el interior del país, hemos visto que se constituyeron filiales de la Asociación Madres de Plaza de Mayo al menos desde 1982 y con más fuerza en la posdictadura. En los casos analizados, se trató de un desprendimiento de una organización previa -local o filial de otro organismo- surgida durante la última dictadura.

A causa de los debates que se venían desarrollando, y de los que surgieron en el contexto abierto por la derrota en la guerra de Malvinas y por el iniciado con la asunción del gobierno elegido democráticamente, y a partir de la diversificación de los objetivos de quienes componían las organizaciones, algunos de sus integrantes se fueron alineando con distintas agrupaciones del movimiento de derechos humanos y 
conformaron filiales de ellas en distintas ciudades. Por un lado, impactaron aquellos debates suscitados en torno a las medidas del gobierno de Raúl Alfonsín -sobre todo, la constitución de la CONADEP, el Juicio a las Juntas y la ley 23466 de reparación económica para cónyuges e hijos de detenidos-desaparecidos-. Por otro lado, aunque vinculados con estos, tuvieron peso los debates por la reivindicación o no de la militancia de los detenidos-desaparecidos, por las consignas que debían seguir manteniéndose en la posdictadura -en especial, "Aparición con vida"-, y por las exhumaciones de tumbas NN, entre otros. A su vez, la constitución de filiales en los años ochenta se dio en el marco de los debates internos de Madres de Plaza de Mayo en torno a los objetivos, desafíos, búsquedas y posicionamientos, que derivaron en una división de Madres de Plaza de Mayo en Asociación y Línea Fundadora en el año 1986, en la cual varias filiales se identificaron con la línea liderada por Hebe Pastor de Bonafini, quien a su vez venía sufriendo cuestionamientos a su forma de conducir la Asociación.

Si bien puede decirse que durante la última dictadura y en la inmediata posdictadura existió una política de expansión de la Asociación Madres de Plaza de Mayo -aunque no solo de esta organización- hacia otras localidades por fuera de la capital del país y de la capital de la provincia de Buenos Aires, también puede alegarse que en varias ciudades importantes dicha organización no se conformó hasta 1985-1987, como en el caso de Rosario y Santa Fe, o que bien en otras, como Córdoba, no se conformó una filial de la Asociación, aunque sí de otras organizaciones. No es menos cierto entonces, como hemos visto, que el proceso de surgimiento y desarrollo de las filiales estuvo relacionado a su vez con las propias características de las ciudades, en las que se generaron alianzas, vínculos y tensiones particulares entre los integrantes del movimiento de derechos humanos local.

De este modo, las filiales de la Asociación Madres de Plaza de Mayo tuvieron surgimientos distintos a causa de los contextos locales, que en parte marcaron los tiempos, los modos, las acciones, las estrategias, las alianzas y el impacto de dicha Asociación en el entramado político-social de cada ciudad. Es evidente que desde la dictadura algunos familiares de detenidos-desaparecidos de distintas localidades intentaron difundir acciones y discursos similares a los que ya circulaban, como el uso del pañuelo blanco sobre la cabeza de las mujeres o marchas para visibilizar las demandas. En este sentido, coincidimos con quienes sostienen que es posible interpretar el desarrollo de los repertorios de acción del movimiento de derechos humanos en distintas localidades como una conjunción de su carácter mimético -traslado de experiencias de una localidad a otray su carácter adaptativo -adecuación de los repertorios de acción a las características de la localidad- (Alonso, 2018). Esto no quiere decir que en cada localidad se hayan reproducido las mismas características generales, sino que existen tendencias, combinaciones y similitudes que deben seguir investigándose para obtener una explicación más compleja del proceso de formación y desarrollo del movimiento de derechos humanos. Consideramos que en el caso de las filiales de la Asociación, esa circulación de experiencias se produjo en especial por la participación en los Encuentros Nacionales que desde 1981 desarrollaba la Asociación en distintas localidades, por la participación también desde ese año en las Marchas de la Resistencia en la Capital Federal -ocasión en la que volvían a compartir una acción con militantes de otras localidades- y por las visitas "al interior" de Madres provenientes de la ciudad de La Plata y Capital Federal, en especial de la presidenta de la Asociación.

Las causas que llevaron a la expansión de filiales de Madres durante los años ochenta no fueron las mismas en todas las localidades en las que se conformaron. En aquellas localidades en las que la filial se constituyó durante la dictadura, las razones se encuentran cercanas a la necesidad de ocupar el espacio público y los consiguientes cuestionamientos respecto a la "inmovilidad" de los organismos existentes y a la ineficacia de las acciones. Por su parte, en las conformadas en la posdictadura tuvieron un mayor peso la disolución o debilidad de otras organizaciones de derechos humanos, las relaciones tempranas con la Asociación Madres de Plaza de Mayo entabladas a partir de viajes a la Capital -pero también de la presidenta al resto de las provincias de la Argentina- y las críticas a las posturas más moderadas de otros organismos, que impulsaron debates en torno a la CONADEP y la consigna "Aparición con vida”. De esta forma, vimos que la opción por la acción 
directa propia de la Asociación es una de las causas en distintas localidades, pero que no tuvo incidencia en la formación de la filial en otras ciudades, como Mar del Plata.

Así como no todas las personas que tenían un familiar desaparecido se organizaron colectivamente, es evidente que no todas las mujeres argentinas que tenían algún hijo detenido-desaparecido se organizaron en la Asociación Madres de Plaza de Mayo, así como no todas sus integrantes estaban enlazadas por ese vínculo primario. Varios autores han señalado que las respuestas más extendidas entre los familiares de detenidos-desaparecidos durante la última dictadura fueron, más que la lucha y la organización, la negación, el sentimiento de impotencia, la depresión, e incluso la enfermedad, la muerte o el suicidio (Gorini, 2006), y que sólo fue una minoría la que decidió dar una respuesta política a la represión, es decir, que decidió asumir la dimensión política que implicaba la búsqueda del familiar iniciada en el contexto de dictadura. A su vez, debe tenerse en cuenta que en el camino de posicionamientos y definiciones algunas mujeres-madres de detenidos-desaparecidos optaron por seguir un camino de organización y lucha en otros organismos, como Familiares de detenidos-desaparecidos o Abuelas de Plaza de Mayo. Las mujeres que optaron por organizarse en la Asociación Madres de Plaza de Mayo -que no necesariamente eran madres biológicas de un detenidodesaparecido, como ocurrió en Tucumán y Mar de Plata- lograron conformar, a lo largo de los años ochenta, una identidad y una memoria colectiva basada en los años de experiencia y lucha conjunta en torno a un discurso ético-político determinado y unas acciones colectivas acordes, fundadas en consignas específicas que las diferenciaron del resto del movimiento de derechos humanos, en especial la negación a recibir reparaciones económicas por parte del Estado por la desaparición del familiar, la negación a la realización de homenajes póstumos a los detenidos-desaparecidos y la negación a llevar adelante exhumaciones de cadáveres NN con el fin de identificarlos.

Pese a los grandes avances que se han logrado, consideramos que aún son necesarias más investigaciones que hagan foco en las distintas localidades donde se conformó una filial de la Asociación para tener un panorama más acabado, puesto que en la década del ochenta existía una veintena de filiales -algunas de las cuales se distanciaron en los años noventa a raíz de diferencias de criterio con la conducción de la Asociación- pero sólo existen trabajos que aborden la experiencia de unas pocas. Profundizar nuestro conocimiento sobre los modos de organizarse resulta indispensable para un análisis más profundo de una de las organizaciones más emblemáticas nacida durante la última dictadura argentina.

\section{Fuentes CitadAs}

A 35 años de lucha, Madres de Plaza de Mayo La Rioja realizan una marcha (19 de diciembre de 2018). El Independiente. Recuperado de http://www.elindependiente.com.ar/pagina.php?id=196661.

Abuelas de Plaza de Mayo (10 de octubre de 1985). Carta a filiales.

Abuelas de Plaza de Mayo (noviembre de 1981). Informe presentado en el II Congreso Latinoamericano de Familiares de desaparecidos.

Adoptarían diligencias en Tucumán por los cadáveres sin identificar (14 de mayo de 1983). La Prensa.

APDH (26 de julio de 1984). Proyecto de ampliación y modificación orgánica del estatuto de la APDH.

APDH (marzo de 1986). "Diez años de lucha en defensa de los derechos humanos. X aniversario APDH". Sesión especial del Consejo de Presidencia.

Asociación Madres de Plaza de Mayo (noviembre 1983). Intervención. Tema I: Intercambio de información y experiencias entre las asociaciones de familiares. IV Congreso Latinoamericano de familiares de detenidos-desaparecidos. México D. F.

Asociación Madres de Plaza de Mayo filial Mar del Plata (2007). Nuestra lucha de 30 años venciendo la muerte. Recuperado de http://grupoapoyomadresmdp.blogspot.com/2007/11/nuestra-historia.html?m=1

Asociación Madres de Plaza de Mayo (1979a). Acta Constitutiva.

Asociación Madres de Plaza de Mayo (1979b). Declaración de Principios. 
Asociación Madres de Plaza de Mayo (1979c). Estatuto.

Asociación Madres de Plaza de Mayo (s/f). Ideas para un reglamento de filiales.

CELS (febrero de 1980). Averiguaciones en los tribunales de Dolores y en las playas atlánticas.

CPM. Fondo DIPBA. División Central de Documentación, Registro y Archivo. Mesa Ds, Carpeta Varios, Legajo 11.739.

Críticas de una madre de dos desaparecidos a Hebe de Bonafini (7 de diciembre de 1985). La Nación.

Encuentro Nacional de Madres de Plaza de Mayo (XVII) (11 de noviembre de 1987). Página 12.

Hubo una fractura (06 de febrero de1986). Clarín.

Madres de Plaza de Mayo (1980). Encuentro. Casa de Nazaret. Buenos Aires.

Madres de Plaza de Mayo (1984b). VI Encuentro Nacional de Madres. Tucumán.

Madres de Plaza de Mayo (23 de junio de 1985). Encuentro Nacional de Madres. La Plata.

Madres de Plaza de Mayo (abril de 1983). Boletín Informativo. Año I, $\mathrm{N}^{\circ} 4$.

Madres de Plaza de Mayo (diciembre de 1983). Boletín Informativo. Año I, No 12.

Madres de Plaza de Mayo (febrero de 1983). Boletin Informativo. Año I, $\mathrm{N}^{\circ} 2$.

Madres de Plaza de Mayo (marzo de 1982). Boletín Oficial de Madres de Plaza de Mayo. Año III, Nº 9.

Madres de Plaza de Mayo (mayo de 1982). Boletín Oficial de Madres de Plaza de Mayo. Año III, $\mathrm{N}^{\circ} 10$.

Madres de Plaza de Mayo (mayo de 1983). Boletín Informativo. Año I, $\mathrm{N}^{\circ} 5$.

Madres de Plaza de Mayo (noviembre de 1987). Encuentro Nacional de Madres. Tucumán.

Madres de Plaza de Mayo (octubre de 1983). Boletin Informativo. Año I, $\mathrm{N}^{\circ} 10$.

Madres de Plaza de Mayo (septiembre 1984). Boletín informativo. Año II, $\mathrm{N}^{\circ}$ 19-20.

Madres de Plaza de Mayo-Línea Fundadora (1986). Documento interno. Origen de las Madres de Plaza

de Mayo Línea Fundadora. Recuperado de http://www.madresfundadoras.org.ar/pagina/espaol/83

Madres de Plaza de Mayo-Línea Fundadora (noviembre de 1987). Hoja Informativa, $\mathrm{N}^{\circ} 2$.

Madres de Plaza de Mayo Línea Fundadora visita la Universidad de Georgia (16 de junio de 2009).

Recuperado de http://www.fondation-besnard.org/spip.php?article766

Madres: prohíben su entrada a Chile (14 de mayo de 1983). Clarín.

Niegan escisión (7 de febrero de 1986). Clarín.

Se cumplen 34 años de la Filial La Rioja de Madres (3 de enero de 2018). El Independiente. Recuperado de http://elindependiente.com.ar/pagina.php?id=161433.

Síntomas de división entre las Madres de la Plaza de Mayo (8 de febrero de 1986). El País.

Viola, igual a Videla: Madres de Plaza de Mayo (16 de octubre de 1981). Unomásuno.

\section{REFERENCIAS}

Águila, G. (2015). Las escalas de análisis en los estudios sobre el pasado reciente: a modo de introducción. Avances del Cesor, $X I I(12), 91-96$.

Alonso, L. (2006). Defensa de los derechos humanos y cultura politica: entre Argentina y Madrid, 1975-2005 (Tesis de Maestría en Historia Latinoamericana). Universidad Internacional de Andalucía, Sede Iberoamericana Santa María de la Rábida, España. Recuperado de https://dspace.unia.es/handle/10334/187?show=full

Alonso, L. (2008). El surgimiento del movimiento argentino de los derechos humanos en perspectiva comparada. Páginas. Revista Digital de la Escuela de Historia, 1, 87-109.

Alonso, L. (2011). Luchas en plazas vacias de sueños. Movimiento de derechos humanos, orden local y acción antisistémica en Santa Fe. Rosario: Prohistoria.

Alonso, L. (2015). Redes y dimensiones espaciales en la movilización por los derechos humanos en Argentina. Avances del Cesor, XII(12), 117-139. 
Alonso, L. (2018). Las luchas pro derechos humanos. Logros y perspectivas de sus estudios. En: G. Águila, L. Luciani, L. Seminara y C. Viano (Compiladoras). La historia reciente en Argentina. Balances de una historiografía pionera en América Latina (pp. 109-128). Buenos Aires: Imago Mundi.

Andreotti Romanin, E. (2013). Memorias en conflicto. El movimiento de derechos bumanos y la construcción del Juicio por la Verdad de Mar del Plata. Mar del Plata: EUDEM.

Areta, M. G. (2002). Movimiento de Derechos Humanos en Neuquén (Tesis de Licenciatura en Sociología). Argentina, La Plata, Universidad Nacional de La Plata. Recuperado de http://www.memoria.fahce.unlp.edu.ar/tesis/te.4 99/te.499.pdf

Azconegui, M. C. (2009). De madres de desaparecidos a Madres de Plaza de Mayo. La definición de identidades en el seno de la Asamblea Permanente por los Derechos Humanos filial Neuquén y Alto Valle. Ponencia presentada en XII Jornadas Interescuelas/Departamentos de Historia. San Carlos de Bariloche.

Azconegui, M. C. (2011). Derechos humanos, política y religión en Neuquén. Ponencia presentada en XIII Jornadas Interescuelas/Departamentos de Historia. Universidad Nacional de Catamarca. San Fernando del Valle de Catamarca.

Boholavsky, E. y Lvovich, D. (2017). La historia reciente argentina a escala regional (1973-1983). En S. Bandieri y S. Fernández (Compiladores). Historia argentina en perspectiva local y regional. Nuevas miradas para viejos problemas. Tomo 2 (pp. 215-238). Buenos Aires: Teseo.

Bravo, N. (2001). Los derechos humanos en la Argentina, de 1976 a 2001: discursos y prácticas (Tesis de grado). Universidad Nacional de Cuyo. Mendoza, Argentina. Recuperado de https://bdigital.uncu.edu.ar/fichas.php? idobjeto $=3937$

Castro, R. (2004). Con vida los llevaron. Memorias de madres y familiares de detenidos-desaparecidos de San Salvador de Jujuy, Argentina. Buenos Aires: La Rosa Blindada.

Codoni, M. S. (2015). Posdictadura argentina: politicas de derechos humanos y el cisma de Madres de Plaza de Mayo. Washington: Georgetown University.

Crenzel, E. (2008). La historia politica del Nunca Más. La memoria de las desapariciones en la Argentina. Buenos Aires: Siglo XXI.

D'Antonio, D. C. (2007). Las Madres de Plaza de Mayo y la maternidad como potencialidad para el ejercicio de la democracia política. En M. Bravo, F. Gil Lozano y V. Pita (Comps.). Historias de luchas, resistencias y representaciones. Mujeres en la Argentina, siglos XIX y XX (pp. 283-303). Tucumán: Editorial Edunt.

Del Carmen, J. y Chironi, J. M. (2016). La Asociación de Familiares y Victimas del Terrorismo de Estado de ViedmaPatagones: Un recorrido posible. Ponencia presentada en el IX Seminario Internacional Políticas de la Memoria. Buenos Aires.

Escher, F. (2009). La Asociación Madres de Plaza de Mayo durante la transición democrática en la Argentina, controversia en torno a la CONADEP. Ponencia presentada en V Jornadas de Jóvenes Investigadores. Buenos Aires, Universidad de Buenos Aires.

Franco, M. (2008). El exilio. Argentinos en Francia durante la dictadura. Buenos Aires: Siglo XXI.

Franco, M. (2018). El final del silencio. Dictadura, sociedad y derechos humanos en la transición (Argentina 1979-1983). Buenos Aires: Fondo de Cultura Económica.

Gorini, U. (2006). La rebelión de las Madres. Historia de las Madres de Plaza de Mayo. 1976-1983. Buenos Aires: Norma.

Gorini, U. (2011) La otra lucha. Historia de las Madres de Plaza de Mayo. 1983-1986. Buenos Aires: Norma.

Jensen, S. (2010). Los exiliados. La lucha por los derechos humanos durante la dictadura. Buenos Aires: Sudamericana.

Kotler, R. (Comp.) (2014). En el país del sí me acuerdo. Los orígenes nacionales e internacionales del movimiento de derechos humanos argentino: de la dictadura a la transición. Buenos Aires: Imago Mundi.

Kotler, R. (2018). Huellas de la memoria en la resistencia antibussista. Historia del movimiento de derechos humanos en Tucumán. 1976-1999. Buenos Aires: Imago Mundi.

Madres de Plaza de Mayo (2017). Encuentros Nacionales. Buenos Aires: Cooperativa Gráfica del Pueblo. 
Madres de Plaza de Mayo (2007). Luchar siempre. Las Marchas de la Resistencia. 1981-2006. Buenos Aires: Ediciones Madres de Plaza de Mayo.

Madres de Plaza de Mayo Línea Fundadora (2014). Las viejas. Madres de Plaza de Mayo Linea Fundadora cuentan una historia. Buenos Aires: Marea.

Mereb, A. (2018). El movimiento de derechos humanos y la construcción de las memorias de la represión en clave local. La resistencia "jipuche” en El Bolsón de la posdictadura argentina. Nuevo Mundo Mundos Nuevos. Recuperado de https://journals.openedition.org/nuevomundo/72891

Mombello, L. C. (2003) La capital de los derechos humanos. En E. Jelin y P. del Pino (Comps.). Luchas locales, comunidades e identidades (pp. 209-231). Madrid: Siglo XXI.

Mora, B. (2005). Juicios por la verdad histórica, rituales de la memoria. La reaparición de una trama en Mar del Plata (Tesis de Licenciatura). Buenos Aires, Argentina. Universidad de Buenos Aires.

Morales, M. A. (2010). La participación femenina en los movimientos por los derechos humanos en La Pampa contemporánea. La Aljaba, Segunda época, XIV, 157-172.

Ochoa, C. A. (1996). Historia de las entidades de Derechos Humanos en Rosario (1973-1983). En I. Antognazzi y R. Ferrer (Comps.). Argentina. Raices históricas del presente. Rosario: Universidad Nacional de Rosario.

Oviedo, S. y Solis, A. C. (2007). La génesis de los organismos de Derechos Humanos en Córdoba. La Bastilla. Revista de Historia y Politica, 1, 99-123

Scocco, M. (2018). La conformación del movimiento de derechos humanos de Rosario (1970-1985) (Tesis de doctorado). Rosario, Argentina. Universidad Nacional de Rosario.

Scocco, M. (2016). El viento sigue soplando. Los orígenes de Madres de Plaza 25 de Mayo de Rosario (1977-1985). Rosario: Último Recurso.

Sikkink, K. (2003). La dimensión trasnacional de los movimientos sociales. En E. Jelin (Compiladora). Más allá de la nación: las escalas múltiples de los movimientos sociales (pp. 301-335). Buenos Aires: del Zorzal.

Sikkink, K. (1996). La red internacional de derechos humanos en América Latina: surgimiento, evolución, efectividad. En E. Jelin y E. Hershberg (Compiladores). Construir la democracia (pp. 71-96). Caracas: Nueva Sociedad.

Solis, A. C. (2011). Del sentido histórico a la agenda ampliada: la experiencia de la Mesa de Trabajo por los Derechos Humanos de Córdoba. Ponencia presentada en XIII Jornadas Interescuelas. Catamarca.

Solis, A. C. (2014). De las comisiones a los organismos en Córdoba: derechos humanos, dictadura y democratización. En Kotler, R. (Comp.) En el país del sí me acuerdo. Los orígenes nacionales e internacionales del movimiento de derechos humanos argentino: de la dictadura a la transición (pp.129-156). Buenos Aires: Imago Mundi.

Solis, A. C. (2016). Hacia una historia más comprensiva del MDH en Córdoba. Ponencia presentada en IX Seminario Internacional Políticas de la Memoria. Buenos Aires.

Zarranz, L. (2018). El mundo es un pañuelo. Viajes al exterior de las Madres de Plaza de Mayo. Tomos I y II. La Plata: EDULP.

Zubillaga, P. (2019a). Las escalas de análisis en los estudios del movimiento de derechos humanos. El potencial explicativo de hacer foco en lo local. En R. Badano (Comp.). Educación Superiory Derechos Humanos. Reflexiones, apuestas y desafios (pp. 297-316). Paraná: UADER-Red Interuniversitaria de Derechos Humanos/CIN.

Zubillaga, P. (2019b) Orígenes y consolidación de la Asociación Madres de Plaza de Mayo de Mar del Plata. Estrategias locales y construcción politica-identitaria (1976-1989) (Tesis de Maestría en Historia y Memoria). La Plata, Argentina. Universidad Nacional de La Plata.

Zubillaga, P. (2017). Aquí no es cuestión de antropólogos sino de política. La Asociación Madres de Plaza de Mayo filial Mar del Plata frente a las exhumaciones de NN en la ciudad en 1985. Revista de Historia, (18), 103-132.

Zubillaga, P. (2016). Los estudios sobre el movimiento de derechos humanos argentino. Un estado de la cuestión. Cambios y Permanencias, (7), 220-239. 


\section{Notas}

1 Nos referimos al Centro de Estudios Legales y Sociales (CELS), la Asamblea Permanente por los Derechos Humanos (APDH), el Movimiento Ecuménico por los Derechos Humanos(MEDH), la Liga Argentina por los Derechos del Hombre (LADH), Madres de Plaza de Mayo, Abuelas de Plaza de Mayo, Familiares de Detenidos y Desaparecidos por Razones Políticas y el Servicio de Paz y Justicia (SERPAJ), lo cual ha dejado a un lado el estudio de la organización de otros espacios de defensa de los derechos humanos, sobre todo fuera de la Capital Federal y la ciudad de La Plata. En algunos pocos casos se suma al Movimiento Judío por los Derechos Humanos como "alternativa” al MEDH. Asimismo, aquellos estudios posteriores al surgimiento de la agrupación HIJOS a mediados de los 90 la incorporan al referirse al movimiento de derechos humanos. Cabe destacar que las mismas organizaciones capitalinas hacían referencias durante los últimos años de la dictadura a las "ocho organizaciones" en sus comunicados, solicitadas y correspondencia. Por cuestiones de espacio, no citaremos aquí todos los documentos de dichas organizaciones que hacen mención a ese número, pero pueden consultarse, entre otros, en el Archivo CELS y en el Archivo Memoria Abierta.

2 La Asociación ha editado varios libros sobre su historia. Se puede ver el catálogo en línea en la página web oficial de la Asociación: http://www.madres.org. También Madres de Plaza de Mayo-Línea Fundadora ha dado su propia versión de la historia de la organización: véase Madres de Plaza de Mayo Línea Fundadora (2014). Para un estado de la cuestión sobre los estudios en torno a las Madres de Plaza de Mayo, véase Zubillaga (2019b).

3 Las explicaciones cuyos principales rasgos han sido convertidos en nacionales de manera poco reflexiva o sin que mediara una constatación empírica no se limitan a aquellas en torno al movimiento de derechos humanos, sino que abarcan también a las referidas a los procesos ocurridos entre 1973 y 1983 en general. Para una síntesis de la producción más relevante de estudios locales y regionales sobre ese período, véase Boholavsky y Lvovich (2017).

4 Como veremos más adelante, la Asociación Madres de Plaza de Mayo estableció que las filiales podían ser regionales o locales, debían contar con un grupo de al menos cinco personas, enviar una solicitud a la Comisión Directiva, fijar un domicilio legal y adherir formalmente a la Declaración de Principios y al Estatuto de la Asociación. Las filiales podían establecer contactos y realizar actividades con otras instituciones, pero las declaraciones públicas debían ser consultadas y aprobadas previamente por la Comisión Directiva Nacional de dicha Asociación. Asimismo, constituir una filial no implicaba financiamiento económico (Asociación Madres de Plaza de Mayo, s/f; 1979a; 1979b y 1979c).

5 Para ampliar sobre los debates mencionados en este apartado, véanse, entre otros autores, Crenzel (2008), Escher (2009), Gorini (2011), Bravo (2001), Codoni (2015), Kotler (2014) y Zubillaga (2017).

6 Algunos medios dieron cuentan inmediatamentede esta división. Véase a modo de ejemplo: Hubo una fractura 6 de febrero de1986). Clarín; Niegan escisión (7 de febrero de 1986); Clarín; Síntomas de división entre las Madres de la Plaza de Mayo (8 de febrero de 1986). El País.

7 Un grupo importante de las Madres consideró que las penas y absoluciones se habían debido a razones políticas. De esta forma, pensaban que con la sentencia los jueces habían servido al propósito del gobierno de hacer las paces con las Fuerzas Armadas. Véase al respecto, Malamud Goti (2000). Las Madres de Plaza de Mayo afirmaron que el gobierno de Alfonsín hizo todo lo posible para limitar la persecución penal a un número insignificante de responsables y consideraron, por el contrario, que debió juzgarse y condenarse a un amplio sector de la ciudadanía que fue cómplice y participe: sacerdotes, abogados, médicos, jueces y empresarios.

8 En los 80 las Madres realizaron algunas acciones de denuncia pública como acto de sanción ética y política, que algunos autores toman como antecedentes de la generalización de dichas acciones en los 90, fundamentalmente por parte de la agrupación HIJOS. Sin embargo, no todas las Madres estaban de acuerdo con el método de "escrache" como práctica política de enfrentamiento cara a cara, lo cual fue motivo de debate en el interior de la Asociación. Por entonces, las Madres sostenían públicamente que, frente a la inacción y lentitud de la justicia, había que identificar a los represores para efectuar una condena moral. Así, con motivo de otra Marcha de la Resistencia en 1985, la presidenta de la Asociación sostuvo: "Y si no conseguimos justicia, pintaremos sus casas, los perseguiremos, nos pondremos en laesquina de sus casas y vigilaremos a sus hijos" (Madres de Plaza de Mayo, 2007, pp. 35-38).

9 Hebe Pastor de Bonafini se desempeña como presidenta de la Asociación Madres de Plaza de Mayo desde su conformación legal como asociación civil en 1979. La votación de las autoridades de la Comisión Directiva al momento de constituirse en Asociación Civil arrojó como resultado su elección como presidenta por el 73,68 \% de los sufragios. La segunda mujer más votada fue María del Rosario América Carballeda de Cerruti, quien obtuvo el 63,15\% de los votos para asumir como Secretaria de la Asociación. Esto puede ser indicativo del nivel de representatividad de Hebe Pastor de Bonafini en el interior del grupo en ese momento (porcentajes calculados a partir de los datos que figuran en el Acta Fundacional de la Asociación Civil Madres de Plaza de Mayo). Sobre la inexistencia de democracia interna y desacuerdos con las formas de conducir de la misma, véanse Hubo una fractura en las Madres de Plaza de Mayo (6 de febrero de 1986). Clarín; Niegan escisión. Criticó Bonafini al grupo disidente ( 7 de febrero de 1986). Clarín; Síntomas de división entre las Madres de la Plaza de Mayo (8 de febrero de 1986). El País; Críticas de una madre de dos desaparecidos a Hebe 
de Bonafini (7 de diciembre de 1985). La Nación; Madres de Plaza de Mayo Línea Fundadora visita la Universidad de Georgia (16 de junio de 2009). Recuperado de http://www.fondation-besnard.org/spip.php?article766; Madres de Plaza de Mayo Línea Fundadora (1986); Madres de Plaza de Mayo Línea Fundadora (2014). Para las diferencias en Santa Fe con la línea de Hebe Pastor por lo que definen como “autoritarismo”, véase Alonso (2014, p. 26).

10 Sistematización realizada a partir de información presente en Zarranz (2018).

$11 \mathrm{La}$ CNU fue una organización antimarxista asociada a la derecha peronista, surgida a fines de los 60 e instalada en Mar del Plata a principios de los 70. Controlaba en esta ciudad diversos sectores de la universidad, el Poder Judicial y algunos sindicatos. Varios de sus miembros formaron parte de las "patotas" encargadas de secuestrar personas en la ciudad antes de la última dictadura y durante ella. Véanse, entre otros, Mora (2005) y Andreotti Romanin (2013).

12 Para declaraciones de las integrantes de la filial riojana véanse, entre otras, Se cumplen 34 años de la Filial La Rioja de Madres (3 de enero de 2018). El Independiente; A 35 años de lucha, Madres de Plaza de Mayo La Rioja realizan una marcha (19 de diciembre de 2018). El Independiente.

13 En Córdoba funcionaron filiales de la APDH, la LADH, Abuelas de Plaza de Mayo y Familiares de Desaparecidos y Detenidos por Razones Políticas. También tuvieron actuación el SERPAJ, el MEDH y, en la posdictadura, una agrupación de expresos políticos, entre otras. Para el movimiento de derechos humanos en Córdoba, véanse los trabajos de Solis $(2011,2014$ y 2016).

14 Abuelas de Plaza de Mayo sí ha derivado fondos a sus filiales desde su autonomización de Madres de Plaza de Mayo -recordemos que compartían el Estatuto, la Declaración de principios y la sede-. De esta forma, hacia 1985 la sede central destinaba 100 dólares mensuales a cada una de sus filiales, las cuales debían realizar un informe financiero mensual (Abuelas de Plaza de Mayo, 10 de octubre de 1985). En cuanto al patrimonio de sus delegaciones, la Asamblea Permanente por los Derechos Humanos estableció en 1984: “Se formará con los aportes voluntarios de los adherentes y servirá para solventar su actividad, sin perjuicio de contribuir en caso necesario al funcionamiento de la APDH nacional" (APDH, 26 de julio de 1984, p. 3).

15 En cuanto al reconocimiento internacional, mencionemos a modo de ejemplo que fueron seleccionadas para el premio Nobel de la Paz y, aunque no lo recibieron, puede pensarse que la sola candidatura ya les otorgaba cierta legitimidad y presencia internacional. Asimismo, tuvieron una audiencia con el papa Juan Pablo II en julio de 1980 y en marzo de 1983, y realizaron diversos viajes por el mundo -Italia, España, Holanda, Bélgica, Noruega, Suiza, Francia, Dinamarca, Suecia, Alemania, Estados Unidos de América, etc.-, en los cuales se reunieron con diversas figuras del ámbito político. Para un detalle de los viajes, véase Zarranz (2018).

16 Decimos que fue "ocupado" porque uno de los aspectos que caracteriza a la Asociación Madres de Plaza de Mayo, y a diferencia de otras organizaciones, es la presencia continua en la calle. Por ejemplo, es inamovible la marcha de todos los jueves.

17 Para 1984, la Asociación contaba con delegaciones en Calilegua, Libertador General San Martín, Concepción del Uruguay, Concordia, Gualeguaychú, Mar del Plata, La Plata, Junín, Chacabuco, Punta Alta, Bahía Blanca, Zárate, San Rafael, Mendoza, Río Cuarto, Villa Mercedes, Salta, La Rioja, San Juan, Neuquén-Alto Valle, San Miguel de Tucumán, Catamarca y Quilmes. A estas debe sumarse la filial Luján-Mercedes y la delegación de Rosario, conformada en 1985. En torno a la cantidad de afiliadas, cabe destacar que, en declaraciones a la prensa en 1981, Laura Armendáriz y Hebe Pastor de Bonafini sostuvieron que, de las aproximadamente 4.000 madres argentinas a las cuales les faltaban sus hijos, 2.500 estaban afiliadas a la Asociación Madres de Plaza de Mayo. Véase Viola, igual a Videla: Madres de Plaza de Mayo (16 de octubre de 1981). Unomásuno. Dos años más tarde las Madres sostuvieron que eran 3.000 asociadas en todo el país (Asociación Madres de Plaza de Mayo, noviembre 1983).

18 Hacia 1984-1985 la APDH contaba con delegaciones en La Plata, Alto Valle-Neuquén, Rosario, Río Colorado, Córdoba, Concordia, Formosa, Chascomús, Chacabuco, La Matanza, Bahía Blanca, Paraná, Concepción del Uruguay, General Pico, Roque Sáenz Peña, Chaco, Santa Fe, General Roca, Viedma, El Bolsón, Corrientes y en la Zona Oeste de la Provincia de Buenos Aires. Para el reconocimiento, participación y patrimonio de las delegaciones de la Asamblea, véase $\mathrm{APDH}, 26$ de julio de 1984.

19 Además de en Buenos Aires, Familiares poseía comisiones, hacia 1984, en Vicente López, Salta, Córdoba, Mendoza, La Matanza, Lomas de Zamora, Olavarría, Avellaneda y La Plata, amén de las ya mencionadas en Tucumán, Rosario y Santa Fe.

20 La organización Abuelas de Plaza de Mayo posee filiales en Mar del Plata, La Plata, Buenos Aires, Rosario y Córdoba. También supo tener filiales en Ayacucho, La Rioja y Mendoza. Cabe destacar que, en sus orígenes, ambas organizaciones tuvieron una relación muy estrecha y fluida en distintas localidades del país. De hecho, el nombre de Abuelas de Plaza de Mayo lo adoptaron en 1980, puesto que así las denominaba la prensa internacional y al interior del país, cuando las acciones específicas las venían realizando desde 1977 como subcomisión. Como escribieron en el informe presentado en el II Congreso Latinoamericano de Familiares de Desaparecidosdesarrollado en Venezuela: "Desde 1980 nuestra Asociación dejó de llamarse 'Abuelas Argentinas con nietitos desaparecidos' para denominarse 'Abuelas de Plaza de Mayo', compartiendo con Madres de Plaza de Mayo sus estatutos y principios, también su sede. Nuestra solidaridad es 
total con ellas e idéntico nuestro reclamo pues somos madres con hijos desaparecidos. Como 'Abuelas' mantenemos total independencia de acción y criterios, así como económica” (Abuelas de Plaza de Mayo, noviembre de 1981).

21 Participaron de dicho Encuentro representantes de las filiales de Mar del Plata, Santa Fe, Rosario, Concordia, Quilmes, Lomas de Zamora, Neuquén, La Rioja, Mendoza, Gualeguaychú, Tucumán, Río Cuarto y La Plata. Encuentro Nacional de Madres de Plaza de Mayo (XVII) (11 de noviembre de 1987). Página 12. 